\title{
Spinal mediation of thermally induced sweating
}

\author{
J R Silver, Walter C Randall, Ludwig Guttmann
}

\begin{abstract}
The sweat responses of nine patients with physiologically complete lesions of the spinal cord (six cervical and three thoracic) were recorded by two different techniques while the patients were exposed to elevated environmental temperatures. Oral temperatures, heart rate and respiration were monitored throughout the observational periods. Oral temperature invariably rose during exposure to heat and both heart rate and respiration tended to increase. Sweating was detected on all of the test areas by both the iodine-starch-paper technique and the quinizarin technique, but it was of widely varying intensity in different portions of the body. In the patients with cervical lesions sweating was generally profuse on the head and neck and occurred in progressively decreasing intensity down to the level of the umbilicus. It was invariably present, but only in very low intensity, on the lower extremity. Sweating was frequently present as a result of manipulation of the patient during the initial preparations, but this generally declined or stopped before the heat was turned on. With application of heat, sweating was recruited on previously dry areas or increased in intensity on those areas in which it was previously present. After oral temperature had increased moderately, the heat was turned off and the doors of the chamber opened widely so that the heat stimulus was suddenly removed. Despite a continued rise in oral temperature, sweating stopped or decreased dramatically. These results are interpreted to indicate the direct mediation by the isolated spinal cord of reflex sweating responses to a heat stimulus applied to the skin. The general distribution of sweating was similar to that associated with distension of the urinary bladder, and careful attention was taken to avoid this complication. The distribution of sweating on the patients with lesions in the thoracic cord was quite different, being most obvious and profuse on the lower extremities and lower trunk and completely absent from the upper trunk, head and upper extremities.
\end{abstract}

Periods of profuse sweating in patients with transverse lesions of the spinal cord were first described in $1917 .^{1}$ This response was elicited by non-thermal stimuli, and was localised to cutaneous regions supplied by the isolated cord. It was believed that this response was a manifestation of the spinal mass reflex.

In 1944 sweating was described in three patients with complete or nearly complete lesions of the cord, and it was concluded that spinal reflex sweating was a pathological release phenomenon which could be induced by almost any afferent stimulus acting on the distal portion of the isolated cord. ${ }^{2}$ The authors believed spinal reflex sweating to be mediated exclusively by the isolated segments of the cord, while thermoregulatory sweating was mediated only by the proximal portion of the cord which was in continuity with the hypothalamus. As a result it was concluded that the upper border of reflex spinal sweating and the lower border of thermal sweating precisely described the level of the cord lesion. It was partially on this basis that the sympathetic dermatomes were described. ${ }^{3}$

In 1947 the important literature dealing with the subject was reviewed and many essential details on blood pressure and peripheral blood flow were added to existing knowledge. ${ }^{4}$ In particular the phenomenon of autonomic dysreflexia was described. It was observed that sweating represented an outstanding component of the symptomatology elicited by visceral stimulation (particularly bladder distension) and noted that the distribution of sweating depended largely upon the distance of the spinal lesion from the cervico-thoracic and the thoraco-lumbar junctions. It was accepted that the spinal cord could mediate reflex sweating but it could not mediate sweating in response to a raised body temperature.

The specific question of thermoregulation in spinal man was examined. ${ }^{5-7}$ These studies demonstrated that a patient with a complete transection of the cord in the cervical region could not sweat or vasodilate his skin blood vessels and was totally unable to maintain his body temperature when exposed to a significantly elevated ambient temperature. These conclusions were confirmed in a short report on a single patient in which "absolutely no sweating" in response to exposure to heat was found. ${ }^{8}$

A further comprehensive study on 57 paraplegic patients including six with complete transections of the cervical cord showed that there was no cutaneous thermo-regulatory sudomotor response mediated by the isolated spinal cord. ${ }^{9}$

Motivated by the question of whether peri- 
pheral thermal receptors participate in the excitation of sweating, patients with surgically proven complete spinal transections were exposed to high ambient temperatures, and sweating on skin regions innervated only by the isolated portion of the cord was found. ${ }^{10}$ The sweating was generally scanty but was observed in every patient studied. These results opposed the concept that the hypothalamus is the sole thermoreceptor in the body for temperature regulation. ${ }^{11}$ However, since all of the patients in this study ${ }^{10}$ had sustained lesions of the thoracic cord (between T3 and T8), the observations have been subject to the criticism that nerves subserving sudomotor responses might exit from the spinal cord above the level of the cord transection and followed a descending course through the sympathetic trunk. Such paramedullary pathways for the mediation of sensation ${ }^{4}$ and autonomic activities ${ }^{3}$ have been suggested. Patterns of sweating elicited by the direct electrical stimulation of the thoracic and lumbar trunk are, however, contrary to this hypothesis. ${ }^{12} 13$

In $1966^{14}$ a further study was carried out. Five patients with complete transections of the cervical cord and two with high thoracic transections were exposed to progressively rising ambient temperatures and sweating was demonstrated in the parts of the body innervated by the isolated cord.

Although the literature contains ample and convincing evidence for the existence of patent pathways for the mediation of reflex sweating by the isolated spinal cord, the cord's ability to activate sudomotor pathways in response to thermal stimuli arising from an elevated ambient temperature remains controversial. This question prompted the present collaborative effort to resolve the problem.

\begin{abstract}
Method
Nine patients were studied. All were inpatients at the National Spinal Injuries Centre, Stoke Mandeville, with established cord transections and no intercurrent illness or complication such as pressure sores. The completeness of the cord transection was determined by clinical examination. Six had sustained physiologically complete lesions of the cervical cord (C5-6) while three had lesions in the thoracic cord ( $\mathrm{T} 1$, $\mathrm{T} 10$, and $\mathrm{T} 12)$. Informed consent was given to the investigation by the patients. Data from the six cervical patients will be emphasised since it is in these patients that the sympathetic outflows are "isolated" from the central control of the brain. It was thus possible to study the ability of the spinal cord to mediate thermal reflexes independently of central control.
\end{abstract}

\section{Sweat Chamber}

The management of the sweat test followed the procedure described by Guttmann. ${ }^{15}$

The sodium salt of quinizarin (2-6-disulphonic acid), the colour indicator, is a redbrown dye and a derivative of anthroquinon similar to alizarin, purpurin and anthraruphin, all of which are used in the dye industry. When applied to the human skin the quinizarin must be mixed with sodium carbonate so that the colour change with moisture may take place whatever the $\mathrm{pH}$ of the sweat secretion; rice starch is also added to economise on the amount of dye that has to be used. The following is the most suitable mixture: quinizarin 2-6disulphonic acid $35 \mathrm{~g}$; sodium carbonate (powdered) $30 \mathrm{~g}$; rice starch $60-70 \mathrm{~g}$.

Due to the affinity of quinizarin for water, the test powder must be stored in absolutely dry and air-tight containers. When performing a test the necessary quantity of powder should be removed from the container, which should be resealed at once. A slight change in colour from red-grey to blue-grey which occurs after a time does not interfere with the usefulness of the mixture.

\section{The Sweat Cabinet}

All tests were carried out in a room set apart for the purpose, to provide standard conditions. The construction of the sweat cabinet was as follows: length $2.06 \mathrm{~m}$; width $1.00 \mathrm{~m}$; height $1 \cdot 14 \mathrm{~m}$.

The patient lies on a trolley within the cabinet, $50 \mathrm{~cm}$ above the floor, and can be moved on this trolley to the bath after the test. The cabinet is timber framed and the walls and ceilings are formed of two thicknesses of plywood separated by $5 \mathrm{~cm}$ air space.

An electrically driven centrifugal fan, mounted in a separate control box with $3.8 \mathrm{~cm}$ bore flexible air is connected to the cabinet. The fan delivers $17 \mathrm{~m}^{3}$ of air per hour, the air being delivered into the cabinet in an upward direction to avoid impinging on the patient; the volume is adjustable by a small damper. A small $75 \mathrm{~W}$ electric heater is fitted in the fan discharge to pre-heat the air to between $32^{\circ} \mathrm{C}$ and $38^{\circ} \mathrm{C}$ before admission to the cabinet. Air is discharged from the cabinet through a small adjustable grill.

The cabinet is heated by banks of carbon filament lamps and tubular heaters which are mounted on the ceiling of the cabinet, which is fitted with a chromium plated reflector; 24-32 candle power, $130 \mathrm{~W}$ carbon filament lamps are provided and controlled in banks of three lamps by switches mounted on the outside of the cabinet. In addition, four tubular heaters, each $1.83 \mathrm{~m}$ long loaded at $200 \mathrm{Wm}^{-1}$ were installed. Experience has shown that the tubular heaters are not as effective as carbon filament lamps for promoting rapid sweating of the patient. A "Cambridge" direct-reading, dial-type thermometer was provided to indicate air temperatures adjacent to the patient. The sweat cabinet ${ }^{4}$ was modified to permit two observers to remain in the chamber with the patient during the entire period. This was accomplished by opening the doors and draping heavy blankets from a fibre-board panel that covered the top.

A Negretti and Zambra hair type, directreading hydrometer was provided for indicating the relative humidity near the patient. 


\section{Position of the Patient}

The position of the patients is important. They must lie comfortably so that the area to be investigated may be inspected easily and the running of sweat from normal or hyperhidrotic areas into anhidrotic or hypohidrotic areas is avoided.

The nude patient rested for approximately 30 minutes on a bed in the sweat chamber at normal ward temperature, while quinizarin powder ${ }^{16}$ was dusted on one side of the body (from midline laterally), and small areas painted with iodine on the other side. ${ }^{17}$ Sweating was thus monitored continuously throughout the observation period by both techniques for its detection. Records were taken by the iodine-starch-paper technique at two to three minute intervals and compared with progressive changes in the quinizarin dye, as well as with the cumulative appearance of the dye at the conclusion of the test period. Oral temperature, pulse rate and respiration were recorded and the experimental period arbitrarily terminated when oral temperature had increased $1-2^{\circ} \mathrm{C}$.

The oral temperature was recorded to avoid any manipulation of the patient's lower limbs or any movement which could provoke a spasm. It was apparent from the outset and from the review of the literature that an important factor to be considered was bouts of autonomic dysreflexia caused by detrusor contraction of the bladder or spasms which could
Table 1 Clinical detail of patients

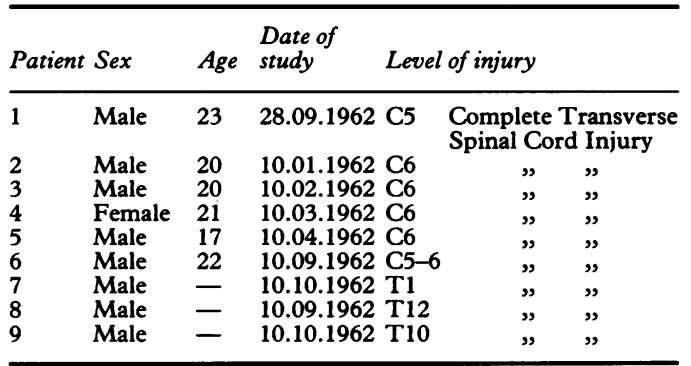

cause sweating. For this reason several of the patients were catheterised at the beginning of the experiment.

After a preliminary control period at room temperature $\left(21-23^{\circ} \mathrm{C}\right)$, the heat was turned on and records of sweating continued throughout the experiment. With some variation from experiment to experiment, the chamber temperature rose from about $20^{\circ}-50^{\circ} \mathrm{C}$ or slightly higher in approximately 30 minutes.

Following this exposure to increasing ambient temperature, the heat was turned off and the chamber opened quickly so that environmental temperatures fell rapidly. Although the patients were unable to detect temperature changes on skin areas below the lesion, they reported normal sensations of cooling on normally innervated areas above the level of the cord transection such as the face. The observers, who invariably sweated

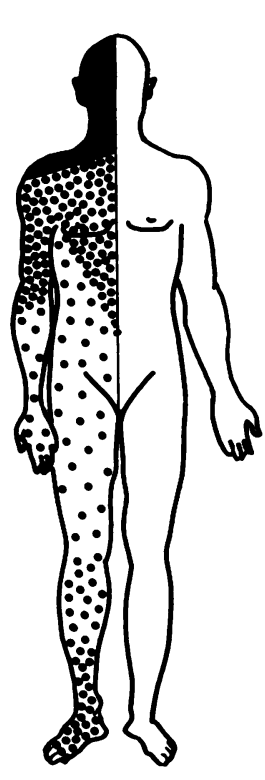

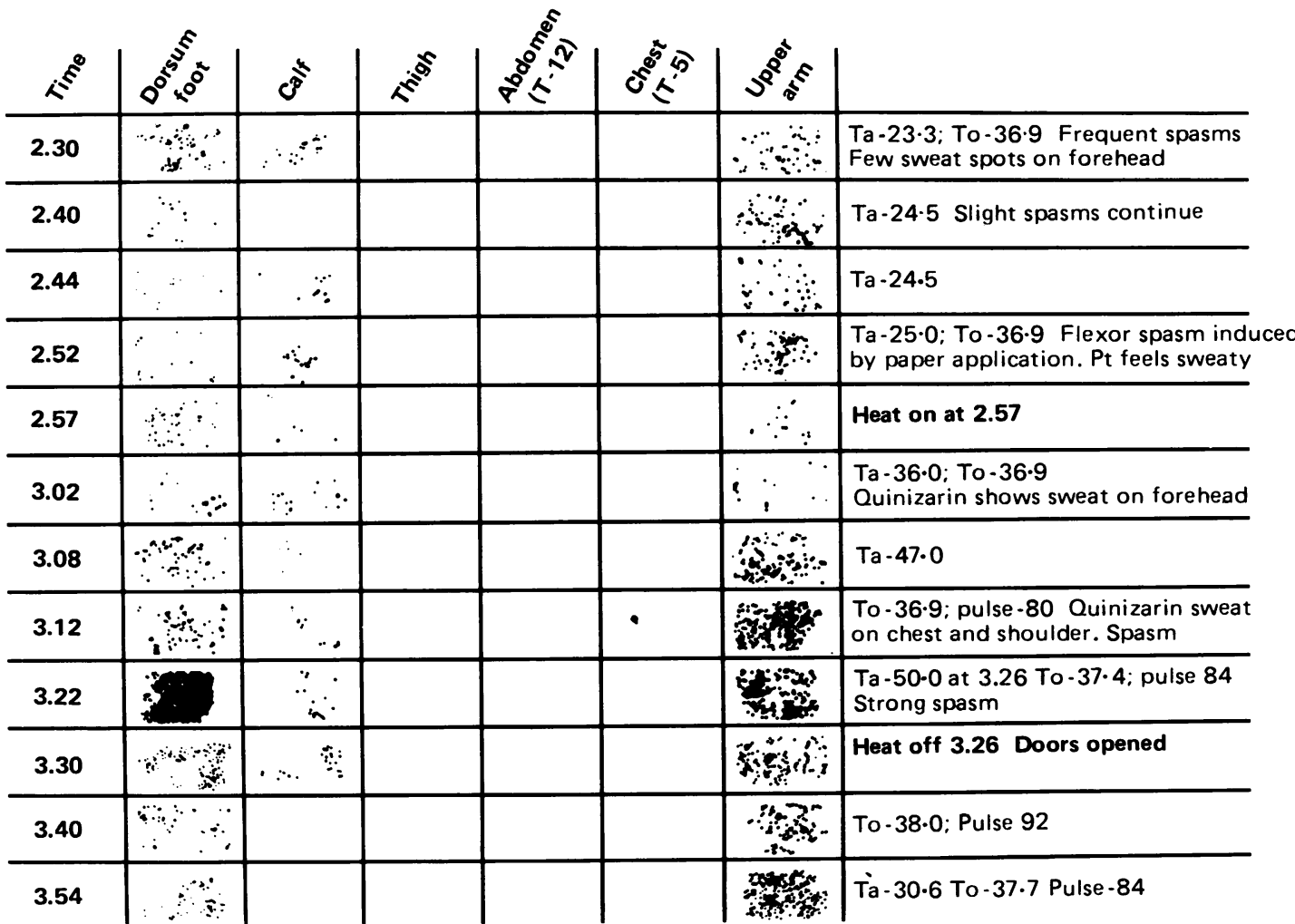

Figure 1 Patient 2. Complete C6 lesion. Not catheterised. Records were not made on the thigh, abdomen, or chest. The figure shows actual records from the iodine-starch-paper technique, mounted on a piece of paper and photographed. This technique reveals low intensity sweating or activity by a relatively few sweat units. Records were selected to illustrate the overall sweating responses during the entire course of the experiment. Ta $=$ Ambient Temperature; To = Oral Temperature.

Figure $1 \mathrm{~A}$ The figure represents the cumulative sweat pattern at the end of the experiment using the quinizarin technique. Black areas = Confluent sweating; Dotted areas $=$ Lesser degree sweating. 


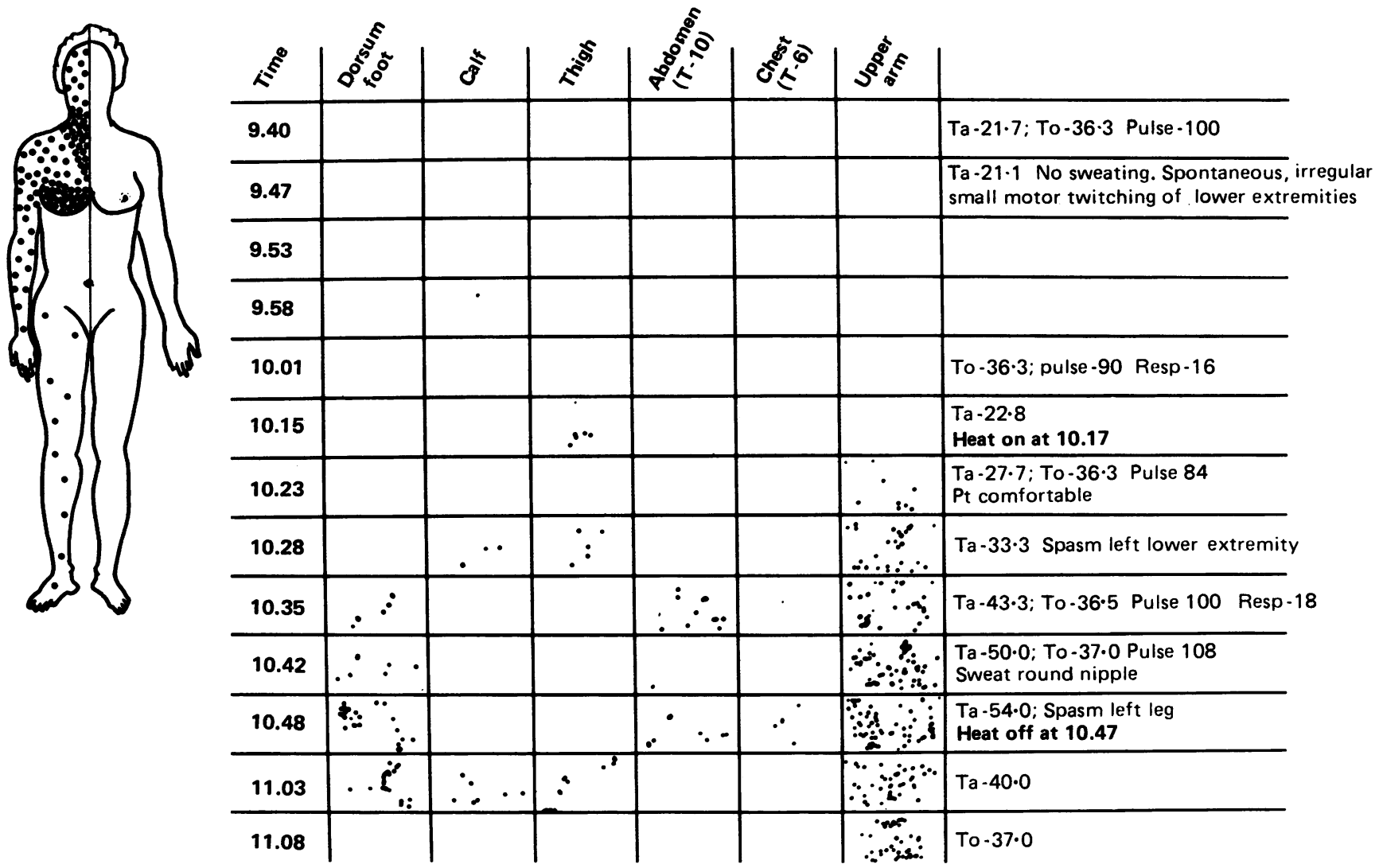

Figure 2 Patient 4. Complete C6 lesion. Catheterised. The figure shows actual records from the iodine-starch-paper technique, mounted on a piece of paper and photographed. This technique reveals low intensity sweating or activity by a relatively few sweat units. Records were selected to illustrate the overall sweating responses during the entire course of the experiment. Ta $=$ Ambient Temperature. To $=$ Oral Temperature.

Figure $2 A$ Represents the cumulative sweat pattern at the end of the experiment using the quinizarin technique. Black areas = Confluent sweating; Dotted areas $=$ Lesser degree sweating.

profusely during the period of heating, reported a feeling of chill as the cabinet doors were opened. This portion of the experimental period is emphasised since it suggests important relationships between the cessation of sweating and the excitation of thermal receptors in the skin.

\section{Results}

The sweating responses representative of the six patients with physiologically complete lesions in the cervical portion of the spinal cord are shown in figs $1-3$. A sketch illustrating the cumulative pattern of sweating, as revealed by the quinizarin method on one side of the body at the end of each experiment, is included in each figure and completes the description of the sudomotor response to heat.

An early study in this series was carried out in a non-catheterised patient (fig 1), which illustrates the complicating influences of uncontrolled alterations in vesicular pressure. There is a relationship between detrusor contractions intravesicular pressure and spasms. ${ }^{418}$ $A$ rise in intravesicular pressure leads to a contraction of the bladder, spasm and autonomic dysreflexia with sweating. Moderate sweating was observed on all of the test areas at the beginning of the control period, and this changed in intensity throughout the experiment. In some instances increases in sweating appeared to be associated with mild to powerful flexor spasms of the lower extremities (Fig 1, time $=2.52$ ). In other instances sweating did not appear to be so associated. Incontinence frequently accompanied the stronger muscular spasms (showing relationship between spasms and bladder contraction). During one such episode in the control period, the patient reported "I feel as though I am going to sweat". He shook vigorously with a strong spasm of the lower extremities, but although there was moderate sweat on the head and neck, sweating patterns did not alter significantly on other areas. During the period of heating, sweating increased in intensity on the dorsum of the foot and on the upper arm and attained an intensity on the foot evaluated as approximately $80-90 \%$ of that which might be expected from a normal subject at similar ambient temperatures. Sweating on the arm simultaneously reached intensities of about $50 \%$. The maximum sweating responses appeared simultaneously with relatively strong flexor spasms of both lower extremities but considerably exceeded that which had been observed during similar spasms before exposure to heat. Thus it became clear that both the incidence and the intensity of sweating may coincide with activity in the flexor muscles, and it is possible that both are associated with the autonomic dysreflexia (the most common cause being contraction of a hollow organ usually the bladder or bowel). At 


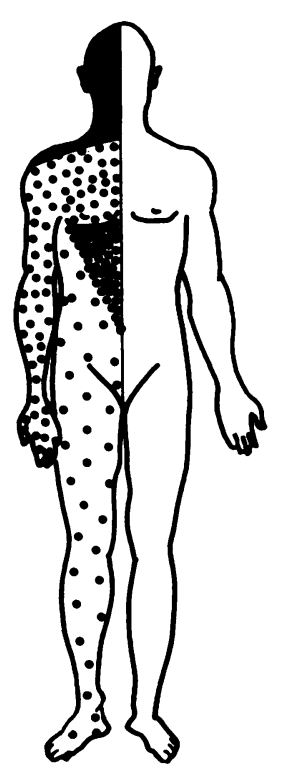

\begin{tabular}{|c|c|c|c|c|c|c|c|}
\hline E & 0 & $\overbrace{}^{*}$ & ثิ & $r^{2}$ & 0 & F & $\begin{array}{l}\text { Pt not catheterised. Slight sweat } \\
\text { during prep for test } \\
\end{array}$ \\
\hline 11.00 & $\because$ & $\therefore \quad \therefore$ & $\therefore$ & & $\therefore \therefore$ & 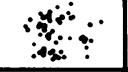 & \\
\hline 11.07 & & $\begin{array}{l}\vdots \\
\therefore \\
\end{array}$ & $\therefore \cdot$ & . بِّ. & 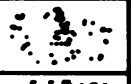 & 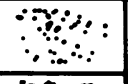 & \\
\hline 11.13 & & $\ddot{\because}:$ & : & 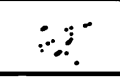 & & 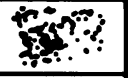 & \\
\hline 11.21 & & & & & $\therefore$ & s.pond & $\begin{array}{l}\text { To-35-8; Pulse -90; Resp-12 } \\
\text { Slight sweat on chest } \\
\end{array}$ \\
\hline 11.31 & & & & & & & $\begin{array}{l}\text { Heat on } 11.39 \\
\text { Ta-24.0 } \\
\end{array}$ \\
\hline 11.40 & & & & & $\therefore \therefore$ & $\sin x$ & Supraclavicular flush \\
\hline 11.48 & $\cdot$ & & & $\vdots \because \because$ & 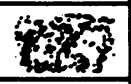 & & To-36.0 Pulse-96 \\
\hline 11.55 & $\therefore \cdot$ & $\therefore \therefore: \therefore$ & $\because \because \because$ & 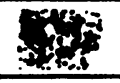 & 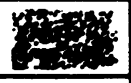 & & Ta-39.4; To 36.4 Pulse 72 Resp-14 \\
\hline 11.57 & 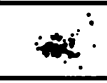 & $\therefore a^{i}$ & $\because \because \vdots$ & & & & Ta $-40 \cdot 0$ To -36.7 Pulse 78 \\
\hline 12.03 & $\therefore$ & $\because \because \because$ &  & 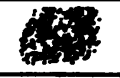 & 象 &  & Ta-48-0; pulse-96 To-36.9; Resp-2C \\
\hline 12.07 & $\begin{array}{r}. \vdots \\
. \quad ! \\
\end{array}$ & & $\therefore$ &  & & sencen & \begin{tabular}{|l|} 
Ta $-48 \cdot 0$ \\
Heat off at 12.07 \\
\end{tabular} \\
\hline 12.13 & & & & & & $\because$ & Ta $-41 \cdot 0$ \\
\hline 12.19 & & & & & & pis & Ta-35.0 To-37.4 \\
\hline 12.24 & & & & & औ & 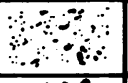 & $\begin{array}{l}\text { To }-37.3 \text { First spasm observed } \\
\text { at } 12.25\end{array}$ \\
\hline 12.36 & & & & & 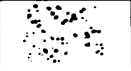 & 隹 & To-37.3 Slight spasm in left leg \\
\hline
\end{tabular}

Figure 3 Patient 6. Complete C5-6 lesion. Not catheterised. The patient was entirely free from spasms until that reported during the 12:24 record. Note relatively profuse sweating on cutaneous areas above the umbilicus and sparse sweating on lower extremity. The figure shows actual records from the iodine-starch-paper technique, mounted on a piece of paper and photographed. This technique reveals low intensity sweating or activity by a relatively few sweat units. Records were selected to illustrate the overall sweating responses during the entire course of the experiment. Ta $=$ Ambient Temperature; $T o=$ Oral Temperature.

Figure $3 \mathrm{~A}$ Represents the cumulative sweat pattern at the end of the experiment using the quinizarin technique. Black areas =Confluent sweating; Dotted areas $=$ Lesser degree sweating.

the conclusion of the experiment the quinizarin dye revealed profuse sweating on the face, neck and shoulders, somewhat less profuse on the chest and arm and in progressively diminishing intensity on the trunk distal to the umbilicus. Sweating was more pronounced toward the midline than on lateral portions of the trunk. Only minute pin-points of sweat were indicated on the distal portion of the upper extremity and on the thigh, with increasing intensity on the distal portions of the lower limb. The oral temperature rose from $36.9^{\circ}$ to $37.4^{\circ} \mathrm{C}$ (fig 1 ) and continued to rise after the discontinuation of heating, to $38^{\circ} \mathrm{C}$.

In contrast, fig 2 represents a patient who was catheterised throughout the experiment to eliminate detrusor contraction of the bladder, when the bladder became distended. She was one of two patients who were completely dry during the preliminary control period. She showed a distinct recruitment of sweating on all of the test areas with application of heat. Sweating first appeared on the upper arms six minutes after the onset of heating, reached a maximum during the maximum chamber temperature and continued for several minutes after it had ceased on other areas. The maximal sweating intensity observed was estimated to be $30 \%$ of what would be expected in a normal subject. Sweating appeared on the lower extremity during the heating period, achieved only minimal intensity and stopped upon cessation of heating. Oral temperature was considered to be subnormal initially and ultimately rose only to normal levels. Sweating was not associated with visible muscular spasms, and the patient felt completely comfortable throughout the period of observation. The quinizarin dye revealed definite, but low, intensity sweating on the face and in somewhat greater intensity in the "blush area" of the neck and chest, and around the nipple. There was very sparse sweating on the arm and leg. Temperature rose from $36 \cdot 3^{\circ}$ to $37 \cdot 0^{\circ} \mathrm{C}$.

In common with earlier authors we observed that the physical manipulation of the patients, in lifting them from the bed to that of the climate chamber, frequently evoked spinal reflex sweating in three of the six cervical patients. Figure 3 illustrates such a slight to moderate sweating on several areas during the control period, but this decreased substantially 


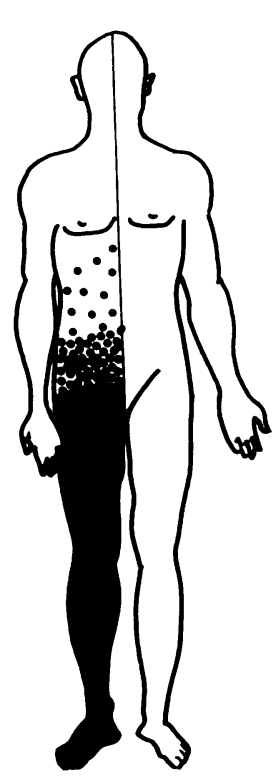

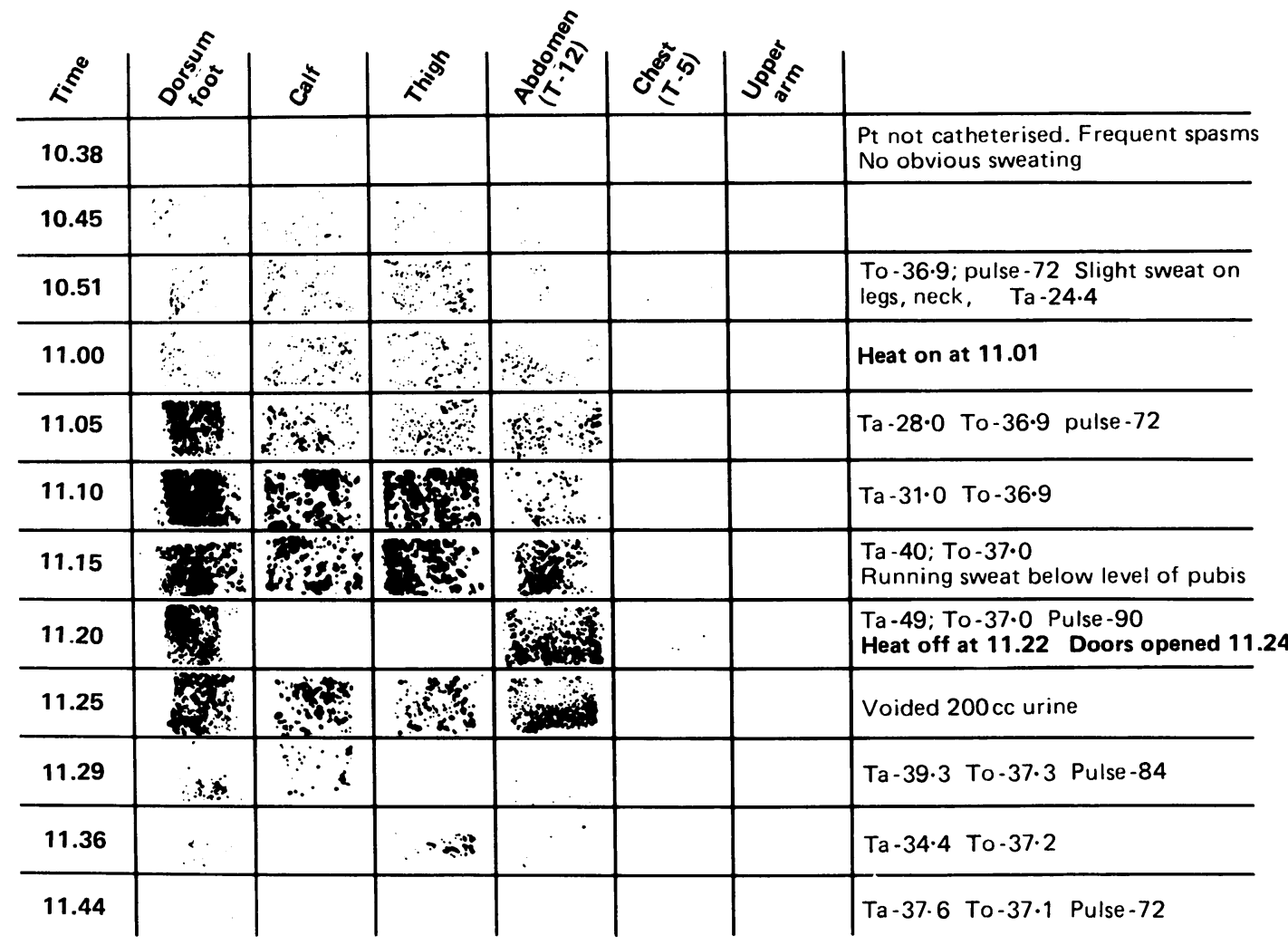

Figure 4 Patient 9. Complete T10 lesion. Not catheterised. Moderate sweating occurred during the pre-heating control period, but this increased considerably with application of heat and stopped promptly upon cessation of heating. Records from the calf taken at 11:20 showed profuse sweating but were omitted from the illustration. Note the complete absence of sweat from the more rostral portions of the body. The figure shows actual records from ihe iodine-starch-paper technique mounted on a piece of paper and photographed. This technique reveals low intensity sweating or activity by a relatively few sweat units. Records were selected to illustrate the overall sweating responses during the entire course of the experiment. Ta = Ambient Temperature; To = Oral Temperature.

Figure 4A Represents the cumulative sweat pattern at the end of the experiment using the quinizarin technique. Black areas = Confluent sweating; Dotted areas $=$ Lesser degree sweating.

or ceased entirely before the heating period began.

Without exception, sweating appeared or increased in intensity on all of the test areas during the application of the external heat stimulus. It was consistently of minimal intensity on the dorsum of the foot, somewhat more intense on the thigh and achieved maximum intensity on the arm and trunk. The quinizarin dye clearly showed profuse sweating on the face and upper chest, extending downward with decreasing intensity to the level of the umbilicus (fig 3 ).

Sweat recruitment during the period of heating appeared early on the face, upper chest and arm, extended down to the T5 dermatome, and still later to the level of the umbilicus (T10-11). The intensity of sweat was also graded, being most profuse on rostral portions as compared with more caudal portions. Sweating was similarly recorded on the lower extremity, being slightly more prominent on the thigh.

It is equally significant that sweating stopped promptly on the lower extremity and abdomen and decreased considerably on the chest and arm following cessation of heating. No spasms were observed until late in the experiment, well after the heat was turned off. Oral temperature rose from $35 \cdot 8^{\circ}$ to $36.9^{\circ} \mathrm{C}$ after the heating was turned off temperature continued to rise to $37 \cdot 4^{\circ} \mathrm{C}$.

In marked contrast to the observations in patients with cervical lesions, patients were studied who had sustained physiologically complete lesions at $\mathrm{T} 10$ and $\mathrm{T} 12$ respectively. Figure 4 illustrates the sweating responses in the patient with lesion at T10, but is qualitatively similar to those observed in the T12 patient as well. The patient was clinically considered spastic and spasms were frequent throughout the test. Sweating was sparsely distributed over the lower extremities during the control pre-heating period, $10 \cdot 45$. Sweating was rapidly and dramatically recruited with exposure to heat, and was most prompt and most profuse on the dorsum of the foot, calf and thigh and least prominent on the abdomen. Only at the end of heat exposure was sweating, and then only slight, recorded from the T5 dermatome on the chest. The entire upper extremity, neck and head remained completely dry throughout. When the heat was turned off and the doors to the climate chamber opened, sweating decreased rapidly and dramatically on all areas studied, although it did not stop completely. Oral temperature had risen only $0 \cdot 1^{\circ} \mathrm{C}$ during the exposure period, but continued to rise an additional $0.3^{\circ} \mathrm{C}$ after the heat was turned off.

Thus sweating did not take place in the normal innervated face, chest and upper limbs, but did so in the partially denervated limbs. Sweating decreased promptly on removal of the external heat stimulus even though the oral 
temperature (internal heat stimulus) was still rising. When the doors of the chamber were opened, the patient voided urine and approximately $200 \mathrm{ml}$ were collected. It is possible therefore that modern bladder distension and the heat stimulus acted synergistically in the facilitation of the thoraco-lumbar sweat centre. At the conclusion of the experiment, the quinizarin dye revealed profuse sweating on the lower extremities with decreasing intensity of sweating rostrally. The face was flushed and the ear lobes warm and pink. Pilomotor activity was periodically observed on the upper chest even though no sweating was elicited.

\section{Discussion}

The discrepancies between earlier reports ${ }^{6}{ }^{10}$ may be due to semantics. To some workers thermoregulatory sweating necessarily infers sufficient evaporative heat loss to prevent significant elevations in body temperature. To others it suggests only the participation of an afferent and efferent sudomotor nervous mechanism, together with central mediation, in eliciting a sweating response to an adequate heat stimulus.

Our studies show that the intensity of sweating in the patient with a complete transection of the cervical cord is certainly not sufficient to prevent an elevation in body temperature, and yet the positive sweating responses to heat were clearly demonstrated.

It should also be emphasised that both the iodine-starch-paper technique and the quinizarin methods were simultaneously employed on all patients and enabled sweating to be demonstrated by both techniques.

Both proved to be exquisitely sensitive as indicators of the onset of sweating, but each has certain advantages which must be considered in the light of the particular objectives desired. The former is capable of detecting, with extreme precision and sensitivity, activity of individual sweat glands and of giving a quantitative evaluation of the overall response in terms of the number of sweat glands excited in a given cutaneous area. It also permits repeated observations over short intervals and therefore makes possible a time-intensity evaluation of the sweat response. The quinizarin technique, on the other hand, combines sensitivity with the ultimate visualisation of the cumulative sweating response of the entire skin surface. Together, the two tests furnish a comprehensive description of the sweating responses under the given experimental conditions. The technique previously described ${ }^{9}$ consisted of inspecting the skin beneath plastic sheeting as the temperature was progressively raised. This technique would not appear to be as sensitive as the techniques that we employed and could explain why small amounts of sweating could be missed.

Patients with complete lesions high in the spinal cord are unable to completely regulate body temperature against heat. As environmental temperature increased rapidly from 22 $23^{\circ} \mathrm{C}$ to about $50^{\circ} \mathrm{C}$, oral temperature rose from a minimum of $0.5^{\circ} \mathrm{C}$ to a maximum of $1.1^{\circ} \mathrm{C}$. Normal subjects exposed to an identical environment show little, if any, elevation during a comparable period of time, and it was shown earlier that patients with mid-thoracic lesions can remain in such an environment for considerably longer periods before central temperatures rise to similar levels. ${ }^{10}$ In all patients, temperatures rose considerably faster towards the end of the exposure and continued to rise for 15-30 minutes after which they were removed from the climate chamber. Sweating did occur (as confirmed by both the quinizarin and iodine-starch-paper techniques) on the entire cutaneous surface below the level of transection in every patient tested. It was minimum in intensity on some areas (primarily on the face, neck, and upper chest).

With complete transection of the spinal cord at mid-cervical levels, sympathetic outflows from the spinal cord must be considered to be completely isolated from the brain, if conventional anatomical description of the site of preganglionic cells is to be accepted. The initiation of sweating with a generalised heat stimulus, together with its disappearance upon removal of the heat stimulus even though oral temperature continued to rise, conclusively demonstrates the existence of thermal reflex sweating in humans. It seems equally clear that the afferent reception of the stimulus occurs in the skin even though we are unable to describe the thermal receptors. It is also apparent that sensory appreciation reaching consciousness of changes in temperature is not essential to the response.

This could suggest that excitation of cold receptors in the skin inhibits firing by preganglionic sudomotor fibres to account for the sudden decrease or cessation of sweating on rapid cooling of the climate chamber or, it is also possible that sweating stops simply because the heat receptors are no longer being adequately stimulated.

The most interesting observation was that sweating stopped or was considerably decreased at the end of the heating period while oral temperature remained $1-3^{\circ} \mathrm{C}$ higher than before the heating began, and in most instances, was still rising after sweating had stopped. This confirms findings of a previous study: ${ }^{14}$ when the cooling process was much slower sweating also ceased but the cut off point was not so sharply demonstrated. There are two possible explanations: either there are cold receptors in the skin, which become activated when the climate chamber suddenly cooled, or the sweating stopped because the heat receptors were no longer being stimulated.

The conclusion of earlier works - that spinal sweating is a component of the mass response and represents a release from supraspinal levels of inhibition, should be re-evaluated to include the concept of graded levels of excitability within the spinal cord. In patients with cervical or high thoracic lesions spinal sweating is distributed in patterns of profuse sweating on rostral areas decreasing caudally with very sparse response on the distal portions of the lower extremities. There is a suggestion that the intensity of spinal sweating and the spread to the lower extremities may be related to the 
intensity of the visceral stimulus. Whether an increased thermal stimulus would elicit correspondingly greater sweating cannot be tested because of the hazard of the implied stress to the patient. With low thoracic lesions, sweating was profuse in the lower trunk and extremities. Such distribution patterns are consistent with the concept of a major sudomotor centre in the cervico-thoracic junction of the spinal cord with a second one at the thoraco-lumbar junction, which was previously proposed. ${ }^{419}$ These concentrations of cells appear to have overlapping cutaneous fields of innervation but with primary distribution to the rostral and caudal areas, respectively. The more rostral of these "centres" is subject to the inhibitory and facilitatory influences of the supraspinal portions of the CNS while the more caudal is the subject of similar influences from the cervico-thoracic "centre". Isolation from the immediate inhibitory influence of the superior area results in excessive activity of the sudomotor nerve cells in response to incoming afferent impulses whether they come from the skin or internal viscera.

There was little overall sweating which would indicate that spinal centres for sweating still depend on central control of the anterior hypothalamus.

It is interesting that sweating in response to heating was recruited in a regional sequence different from that observed previously. In normal subjects ${ }^{20}$ and in paraplegic patients ${ }^{10}$ sweating first appeared on the foot and then successively on the thigh, trunk, upper extremity and face. In none of the earlier patients, however, was the lesion situated in the cervical portion of the spinal cord so that the cervico-thoracic sudomotor centre was separated from the lower thoraco-lumbar centre. Again it appears possible that the more rostral portions of the cord tend to exercise a degree of inhibition over more distal portions.
Indeed, both patients with low thoracic lesions in our studies showed initial recruitment on the distal portions of the lower extremity with successive recruitment in a rostral direction.

1 Head H, Riddoch G. The Autonomic Bladder, excessive sweating and some other reflex conditions, in gross injurie of the spinal cord. Brain 1917;40:188-263.

2 List CF, Pimenta AD. Sweat secretion in Man, VI Spina reflex sweating. Arch Neurol Psychiat 1946;51:501-7.

3 Foerster O. Symptomatologie der Erkrankungen des Ruckenmarks. In: Bumke O, Foerster O, eds. Handbuch der Neurologie, vol 5. Verlag Springer, 1936:1-403.

4 Guttmann L, Whitteridge D. Effects of bladder distension on autonomic mechanisms after spinal cord injury. Brain 1947;70:361-404.

5 Pollock LJ, Boshes B, Cher H, Finkelman J, Arieff AJ, Brown $M$. Defects in regulatory mechanisms of autonomic function in injuries to the spinal cord. I Neurophysiology tion in injuries

6 Guttmann L, Silver JR, Wyndham $\mathrm{CH}$. Thermoregulation in spinal man. $J$ Physiology 1958;142:406-19.

7 Guttmann L. Visceral activity and peripheral circulation in spinal man. Peripheral Circulation in Man-Ciba Symposium, Boston. London: JA Churchill, 1954:192-204.

$8 \mathrm{~W}$ yndham $\mathrm{CH}$. Thermoregulation in the human spinal cord isolated above the thoracic sympathetic outflow. $S$ Afr Med Sci 1955;20:93.

9 Normell LA. The Cutaneous Thermoregulatory Vasomotor Response in Healthy Subjects and Paraplegic Men. Scand $J$ Clin Lab Invest 1974;33:138.

10 Seckendorf $\mathrm{R}$, Randall WC. Thermal reflex sweating in normal and paraplegic man. J Applied Physiology 1961; 16:796-800.

11 Benzinger $\mathrm{TH}$. The thermostatic regulation of human heat production and heat loss. Proc Int Union Physiol Sci 962;1:415-38.

12 Randall WC, Cox JW, Alexander WF, Coldwater KB, Hertzman AB. Direct examination of the sympathetic outflows in man. J Applied Physiology 1955;7:688-98

13 Coldwater KB, Alexander WF, Cox JW, Randall WC. The functional significance of the first thoracic ganglion in sympathectomy of the upper extremity. Ann Surgery 1957;145:530-9.

14 Randall WC, Wurster RD, Lewin RJ. Journal of Applied Physiology 1966;21:985-93.

15 Guttmann L. Management of the quinzarin sweat test. Post Graduate Medical Journal 1947;23:1-14.

16 Guttmann L. A demonstration of the study of sweat secretion by the quinizarin method. Proc $R$ Soc Med secretion by

17 Randall WC. Sweat gland activity and changing patterns of sweat secretion on the skin surface. Am J Physiology 1946;147:391-9.

18 Silver JR. Circulatory reflexes in spinal man. Paraplegia 1964;2:235-46.

19 Guttmann L. The treatment and rehabilitation of patients with injuries of the spinal cord. In: Cope Z, ed. Surgery, $a$ history of the second world war. London: HMSO, 1953.

20 Randall WC, Peiss CN, Rawson RO. Simultaneous recruit ment of sweating and perception of warmth in man. $J$ Applied Physiology 1958;12:385-9. 